\title{
An Empirical study to determine whether ADHD disorder affects the process of language learning
}

\author{
Rachel Marie Paling
}

\author{
"Correspondence author \\ Rachel Marie Paling \\ Efficient Language Coaching \\ UK \\ E-mail: info@efficientlanguagecoaching.com
}

Submitted : 3 Mar 2020 ; Published : 14 Mar 2020

\begin{abstract}
In previous studies, it seems that the classification of ADHD did not appear to interfere with learners'performance in foreign language courses. In this empirical investigation, a group of 43 adult language learners diagnosed with ADHD were asked questions relating to their language learning process, in particular to the difficulties encountered when partaking language courses, as well as subjective opinions as to progress and success relating to the language learning and also what the participants felt could have assisted the learning to make it more effective, efficient and successful. A control group of 43 adult language learners who had not been diagnosed with ADHD were asked the same questions. The findings indicated some significant negativity from the ADHD group with regards to their progress and success with the language learning, as well as an extremely significant statistical difference between the ADHD group and the control group in relation to the difficulty concerning attention while learning. This finding concludes that in fact, language learners diagnosed with $A D H D$ report their difficulty with attention and this would corroborate the attention deficit symptom inherent to this neurobehavioral disorder.
\end{abstract}

Keywords: ADHD, Attention Deficit, Learning a Foreign Language

\section{Introduction}

Attention-deficit/hyperactivity disorder (ADHD) is a neurodevelopmental and neurobehavioral disorder in children, adolescents and adults. In the second edition of the Diagnostic and Statistical Manual (DSM) of Mental Disorders in 1968, (taxonomic and diagnostic tool published by the American Psychiatric Association (APA)), it was called Hyperkinetic Reaction of Childhood and was focused on excessive motor activity symptoms. However, in 1980, in the $3^{\text {rd }}$ edition, it was changed to inattention (not being able to keep focus), hyperactivity (excess movement that is not fitting to the setting) and impulsivity (hasty acts that occur in the moment without thought) and was changed to be called Attention Deficit Disorder with and without Hyperactivity. This in fact eliminated the previously called ADD and reflected the importance of the inattention as well as hyperactivity and impulsivity. The actual term Attention Deficit/ Hyperactivity Disorder (ADHD) was then brought into the $4^{\text {th }}$ edition of the DSM and in the $5^{\text {th }}$ edition in 1994, three specific subtypes of ADHD were specified: predominantly Inattentive; predominantly Hyperactive-Impulsive; combined. The symptoms were then defined as "excessive symptoms of inattention and/or hyperactivity-impulsivity. The most recent release of the DSM was the $5^{\text {th }}$ edition and it includes the latest update to ADHD with changes to the ADHD diagnostic criteria (A-E), a change to the terminology in the ADHD subtype nosology, and the addition of two ADHD modifiers. In the early 2000s, the recognition and diagnosis of ADHD in adults increased and ADHD can be reliably diagnosed in children, adolescents, and adults with the current guidelines in the DSM $5^{\text {th }}$ Edition [1].

An estimated 8.4 percent of children and 2.5 percent of adults have $\operatorname{ADHD}[2,3]$. A diagnosis is based on symptoms manifested over the previous six months and involves getting together information from parents, teachers and others, filling out checklists and having a medical evaluation [4]. According to Tannock, a person with ADHD may be either: restrictively inattentive, with six or more inattentive but a maximum of two of the hyperactive-impulsive symptoms, or; inattentive, with six or more inattentive symptoms but three to five of the hyperactive-impulsive symptoms, or; hyperactive and impulsive, with six or more hyperactiveimpulsive symptoms but five or fewer of inattention; or manifests all symptoms at equal intensity.

According to the APA, there are various symptoms for the Inattentive type, of which six (or five for people over seventeen years) occur frequently. These involve lack of attention or care for detail; making careless mistakes; problems to retain focus; not listening when spoken to, that is, easily distracted; 
not following through on instructions, maybe problems to organize, and problems to sustain mental effort. There could be frequent misplacing of things or forgetfulness. For the Hyperactive/impulsive type, again six symptoms should be identified or five for people over seventeen. These include fidgeting or tapping, maybe the need to keep standing up, running around and always "on the go".

Constant talking and blurting out, displaying impatience or constant interrupting [5]. Through the years, the figures relating to the increase of ADHD rose significantly.

This was seen clearly in the USA, from 1995 with a total number of children on ADHD medication at 1.5 million to 3.5 million in 2011 [6, 7]. Some factors have been identified as connected to ADHD, for example, such as parenting styles, lack of sleep, mobile phone use and poverty [8-11].

About education, it is important that educators are not misinformed about ADHD and it was suggested that a "reinvigorated conceptual understanding of ADHD could help educational institutions to avoid the expensive outsourcing of behavioural problems" [12]. In particular, with foreign language learning, it could be good for educators to learn to identify students with learning differences (LD) and attention disorders (ADHD/ADD), define their language-learning difficulties, and identify types of appropriate intervention strategies [13]. This was reiterated in a study of ADHD of learners of English as a foreign language from Iran, which stated that both parents and teachers in contact with these learners should understand the importance of identifying them and thus planning and monitoring their progress (Marashi and Dolatdoost, 2016).

Previous studies indicated that ADHD might have a negative impact on foreign language learning in college [14, 15]. In 2003, a study compared learning difficulty (LD) students receiving course substitutions for the foreign language requirement at college with students with both LD and ADHD, who had also received the same. The findings showed no difference at all between the two groups relating to foreign language aptitude scores and college foreign language course grades (as well as other things), and in fact the results were contradictory as the LD/ADHD group actually scored significantly higher on IQ scores, reading and math and in fact higher foreign language grades than the LD group [16].

Language learning is broadly defined "as developing the ability to communicate in the second / foreign language and in this context includes: language learning for specialists, for nonspecialists or service languages, for instruction and for social purposes." (LanQua, n.d.). It is the learning of any language per se, although in Language Teaching and Applied Linguistics it refers to the learning of foreign languages. According to Kramina, language learning, which is a conscious process, is the product of either a formal language-learning situation or a self-study programme [17]. It focuses students' attention on the form (structure) of the language. Language acquisition, as opposed to learning, is a subconscious process similar to that by which children acquire their first language.

According to Krashen and other researchers concerning second language acquisition, there are two different ways in which adult second language learners can learn and develop second language skills: one is language learning and the other is language acquisition $[18,19]$. Hussain compares both language learning and language acquisition and highlights the difference, whereby principally language acquisition is an intuitive intake "devoid of any exertion or intention", but language learning is a "cognizant or intentional activity".

To become proficient in a foreign language, there must be knowledge of syntax, vocabulary, phonology, and orthography, to achieve this working memory would play a key role and attention is significantly important in foreign language learning [20, 21]. Sparks, Javorsky and Philips conducted a Comparison of the Performance of College Students Classified as $\mathrm{ADHD}$, LD, and $\mathrm{LD} / \mathrm{ADHD}$ in Foreign Language Courses. Inferences were drawn from this comparison [22]. These were that a student's classification as ADHD might not be indicative of whether he or she can pass Foreign Language courses and/ or fulfil a college's Foreign Language requirement or be a reliable indicator of levels of cognitive ability or academic achievement skills as measured by standardized cognitive ability and achievement tests. Also, ADHD classified students may not exhibit deficits in the language- related skills that have been found to be important for and predictive of successful Foreign Language learning [22].

Kałdonek-Crnjaković discussed the potential cognitive effects ADHD may have on the development of specific language skills in Additional Language Learning and concluded ADHD has a great impact on developing all language skills in Language learning, but that there is inconclusive evidence that individuals with ADHD have specific difficulties in Language learning [23].

\section{Objectives}

Learning a foreign language requires fully functioning executive functions, cognitive skills, memorisation and memory recall. There is the requirement for both explicit and implicit learning input $[18,24,25]$. The question for the present study was to discover if the symptoms of ADHD in adults, affected or impacted in any way the language learning process (for the purposes of this study language learning refers to learning a second language) and to determine what difficulties learners encountered when in a second language learning process, what could assist the language learning and make it more effective and what subjective conclusions learners had regarding their own learning success and successful usage or implementation of the second language after the language learning process had concluded.

\section{Material and methods}

A study was undertaken with 20 questions with two groups of adult language learners. The first group had all been officially diagnosed with ADHD and the second group acted as a control group and had no diagnosis of ADHD. In each group, 43 adult participants took part and each person consented to his or her anonymous participation in the study. 
In the ADHD group, $12 \%$ were male, $81 \%$ female and $7 \%$ nonbinary. Regarding their country of origin, $51 \%$ originated from the United States and the $42 \%$ rest were from 8 other different countries, with $7 \%$ not disclosing their country of origin. Thirty-three percent of this group had been learning Spanish, $23 \%$ French and $11 \%$ had been learning 13 other languages. The mean age of this group was between 31 to 40 years old and in fact, $58 \%$ of this group were between the ages of 31 and 50 .

In the control group, $26 \%$ were male and $74 \%$ were female. There were 21 nationalities involved, $47 \%$ had been learning English and 3\% had been learning 6 other languages.

The mean age of this group was between the age 41 to 50 years old and $81 \%$ of the control group were between the ages 31 to 50 years old.

As an indicator of language level reached, the Common European Framework of Reference for languages was used, as it is one of the widely accepted global standards for grading language proficiency. The beginner level start at $\mathrm{A} 1$ (beginner), then A2 (elementary) and these are classified as the basic user levels. Next is B1 (intermediate) and B2 (upper intermediate), classified as independent user levels and then $\mathrm{C} 1$ (advanced) and $\mathrm{C} 2$ (proficient) classified as proficient user levels. Other classifications used are beginner, fluent, intermediate and unsure.

Both groups were asked what level they had reached. In the ADHD group, $40 \%$ answered they had reached basic level and $21 \%$ had reached proficient user level. In the control group, $9 \%$ had reached basic level and $65 \%$ had reached proficient. Both groups were asked how they had learnt, whether one to one or in groups to comprehend the learning environment of the participants. In the ADHD group, nearly half the group had learnt in a group of more than 12 people, compared to $28 \%$ of the control group. In fact, $66 \%$ of the ADHD had learnt in a group ranging between 2 to more than 12 people (thus, not a one on one private learning setting) compared to $56 \%$ of the control group in a group ranging between 2 to more than 12 people (not one on one).

The participants were then asked if they had achieved their initial language learning goals and the percentages were calculated according to

1. No goals achieved

2. Some goals achieved

3. Most goals achieved

4. Almost all goals achieved

5. All goals achieved. In the ADHD group, $42 \%$ claimed to have reached almost all goals or to have reached all goals compared to $65 \%$ of the control group claiming to reach almost all or all goals.

Both groups were asked what difficulties had been encountered when learning the target language and various categories were given as potential areas of difficulty. These were memory; understanding grammar; attention and focus in the sessions; speaking the language; listening to the language; writing the language; reading texts in the language. Participants were asked to rate the difficulties on a six-point evaluation as follows:

\section{Extremely difficult}

2. Very difficult

3. Difficult

\section{Struggled a bit}

5. Neither difficult nor easy

6. Easy 0. Unsure.

The mean values were calculated for each and the standard deviation to determine the two-tailed $\mathrm{P}$ value and the statistical importance of the results. Participants were then asked what could have been done in the learning process that would have helped to achieve their goals and learn the language faster and more effectively and several suggestions were given: given more time to answer; less oral and more written; less written and more oral; to have one to one sessions; more focus on goals and actions; to have shorter exercises; use multimedia and visual solutions at home. The answers were transformed into percentages.

Finally, relating to new language usage, participants from both groups were asked about their levels of confidence in the target language relating to speaking, reading, writing and listening. They were also asked if they try to avoid speaking/working in the new language learnt and whether they experienced "silent moments" when using the language learned. Additionally, whether learning a new language had helped at work or in a professional capacity and participants were asked to describe their present level of the new language knowledge. The answers were transformed into percentages.

\section{Results}

The participants were asked if they had achieved their initial language learning goals and in the ADHD group, $42 \%$ claimed to have reached almost all goals or all goals compared to $65 \%$ of the control group claiming to have reached almost all or all goals, indicating a higher degree of satisfaction in achieving goals within the control group. In relation to the results relating to the difficulties encountered when learning the target language, the mean values were calculated for each category as well as the standard deviation to determine the two-tailed $\mathbf{P}$ value and the statistical importance of the results. With regard to memory, the 43 participants with ADHD $(\mathrm{M}=2.97, \mathrm{SD}=$ 1.65) compared to the 43 participants in the control group (M $=3.06, \mathrm{SD}=1.42)$ rendered results that were not statistically significant differences, $\mathrm{t}(43)=0.27, \mathrm{p}=0.78$.

Next, looking at the results regarding understanding grammar, the 43 participants with $\operatorname{ADHD}(\mathrm{M}=2.84, \mathrm{SD}=1.79)$ compared to the 43 participants in the control group $(\mathrm{M}=3.12, \mathrm{SD}=$ 1.37) also rendered results that did not demonstrate statistically significant differences, $\mathrm{t}(43)=0.81, \mathrm{p}=0.41$. Regarding oral performance or speaking the target language, the 43 participants with ADHD $(\mathrm{M}=3.30, \mathrm{SD}=1.96)$ compared 
to the 43 participants in the control group $(\mathrm{M}=3.16, \mathrm{SD}=$ 1.40) did not provide results that demonstrated statistically significant differences, $\mathrm{t}(43)=0.38, \mathrm{p}=0.70$.

With regard to the listening, writing and reading of the target language, the results did not display significant differences. So, comprehension through listening to the target language, the results for the 43 participants with ADHD were $\mathrm{M}=3.07$, $\mathrm{SD}=1.86$, compared to the 43 participants in the control group were $\mathrm{M}=2.72, \mathrm{SD}=1.30$ and again no statistically significant differences were obtained, $\mathrm{t}(43)=1.01, \mathrm{p}=0.31$ and the same with regard to writing the target language, the results from the 43 participants with ADHD $(\mathrm{M}=2.95, \mathrm{SD}=1.95)$ compared to the 43 participants in the control group $(\mathrm{M}=2.86, \mathrm{SD}=$ 1.52) did not obtain statistically significant differences, $\mathrm{t}(43)=$ $0.23, p=0.81$. The results for reading the target language for the 43 participants with ADHD were $(\mathrm{M}=2.88, \mathrm{SD}=1.87)$ compared to the 43 participants in the control group $(\mathrm{M}=2.67$, $\mathrm{SD}=1.30)$ and no significant differences, $\mathrm{t}(43)=0.60, \mathrm{p}=$ 0.54 .

However, with regard to difficulties relating to attention, the results were significant and the 43 participants with ADHD $(\mathrm{M}=3.70, \mathrm{SD}=1.41)$ compared to the 43 participants in the control group $(\mathrm{M}=2.23, \mathrm{SD}=1.32)$ obtained extremely statistical significant differences, $\mathrm{t}(43)=4.99, \mathrm{p}<0.0001$. In this case, the ADHD group found greater difficulties to bring focus and attention in the sessions than the control group (see Figures 1 and 2 below).

\section{Focusing in the sessions}

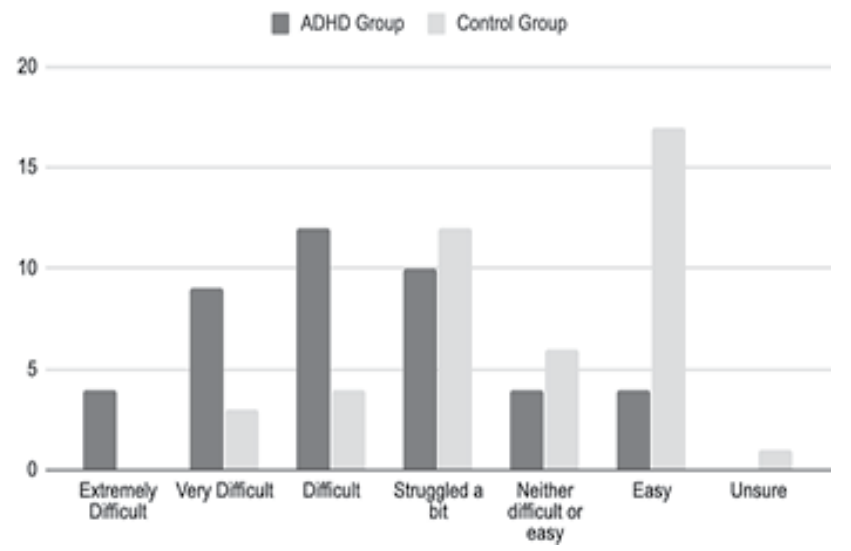

Figure 1: Focusing in the Sessions: Bar Graph displaying the results for Difficulty focusing in the sessions for the ADHD group and the Control Group

\section{Skills: ADHD vs Non-ADHD}

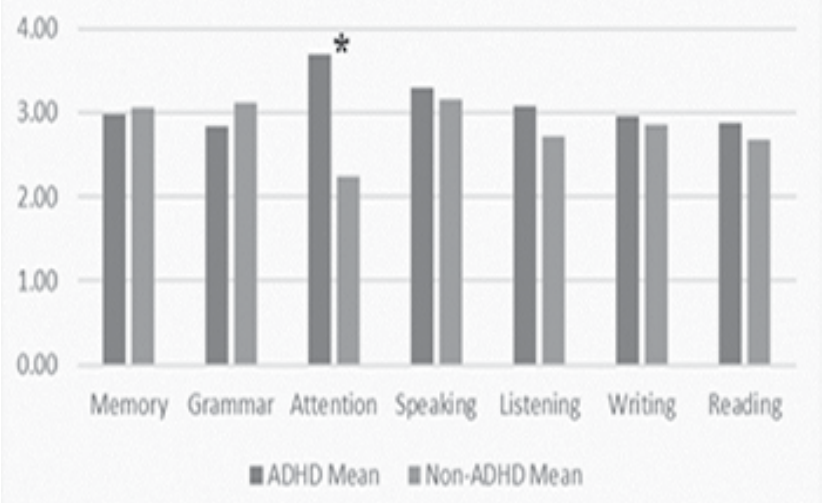

Figure 2: Skills: ADHD vs Non=ADHD: Bar Graph with the Results relating to the difficulties encountered when learning a foreign language for the ADHD Group and the Control Group $* \mathrm{p}<0.001$

When asked what could have been done in the learning process that would have helped to achieve goals and learn the language faster and more effectively, the participants responded as follows. About the question of being given more time to answer, $39 \%$ of the ADHD group answered that this would not have helped, whereas only $23 \%$ of the control group responded in this way. Regarding less oral and more written, $51 \%$ of the ADHD group stated this would not have helped as well as $37 \%$ of the control group.

Relating to having less written and more oral, the answers seemed to be more extreme when comparing both groups, as $48 \%$ of the ADHD group said this could have helped a little $(30 \%)$ and a lot (18\%), whereas only $18 \%$ of the control group stated this could have helped a little.

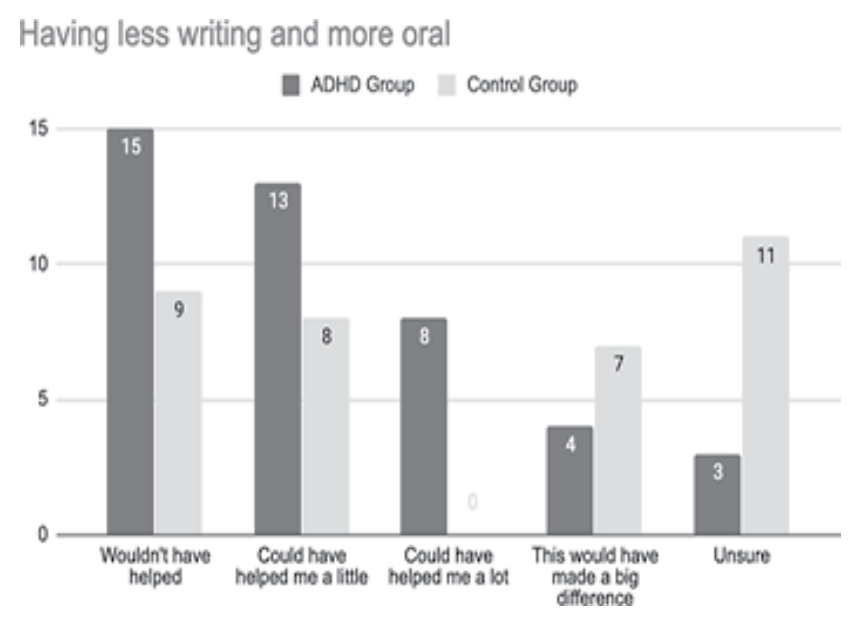

Figure 3: Having less writing and more oral: Bar graph displaying the results to the question relating to whether having less written and more oral could have helped in the language learning process.

In relation to having one to one sessions, $81 \%$ of the ADHD group answered this could have helped a little (18\%), a lot (33\%) and made a big difference (30\%), compared to a total of $53 \%$ of the control group stating that it could have made a 
big difference $(35 \%)$ or it could have helped a little $(18 \%)$. It seems to be significant to the ADHD group to have one to one sessions, as opposed to group sessions.

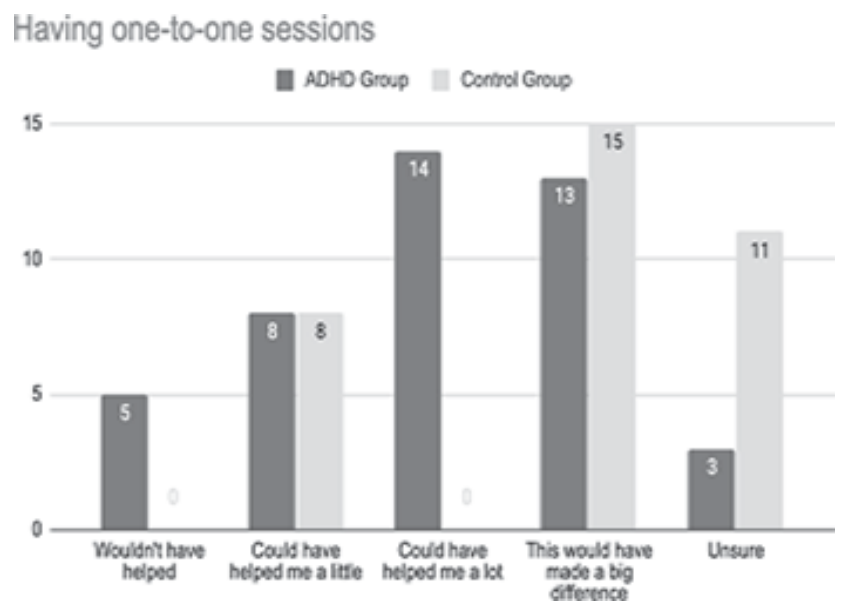

Figure 4: Having one to one sessions: Bar Graph displaying the results to the question whether one to one sessions could have helped in the foreign language learning process.

Relating to more focus on goals and actions and to having shorter exercises, the results were similar for each group, with no significant differences. Relating to using multimedia and visual solutions at home, $42 \%$ of the ADHD group answered that this could have helped a lot, compared to $23 \%$ of the control group.

In terms of confidence with the new language, the results were as follows.

\begin{tabular}{|l|l|l|}
\hline & $\begin{array}{l}\text { ADHD } \\
\text { Group }\end{array}$ & Control Group \\
\hline Not confident & $28 \%$ & $5 \%$ \\
\hline Some confidence & $39 \%$ & $14 \%$ \\
\hline Confident & $7 \%$ & $30 \%$ \\
\hline Good confidence & $7 \%$ & $23 \%$ \\
\hline Very confident & $19 \%$ & $28 \%$ \\
\hline Unsure & $0 \%$ & $0 \%$ \\
\hline
\end{tabular}

Figure 5: Figure displaying the percentages relating to degree of confidence in the acquired target language for both the ADHD Group and the Control Group.

In relation to speaking, it is quite significant to see that $67 \%$ of the ADHD group did not feel confident or had only some confidence in relation to speaking compared to $19 \%$ of the control group not feeling confident or with some confidence.

\section{Speaking \\ ADHD Group Control Group}

20

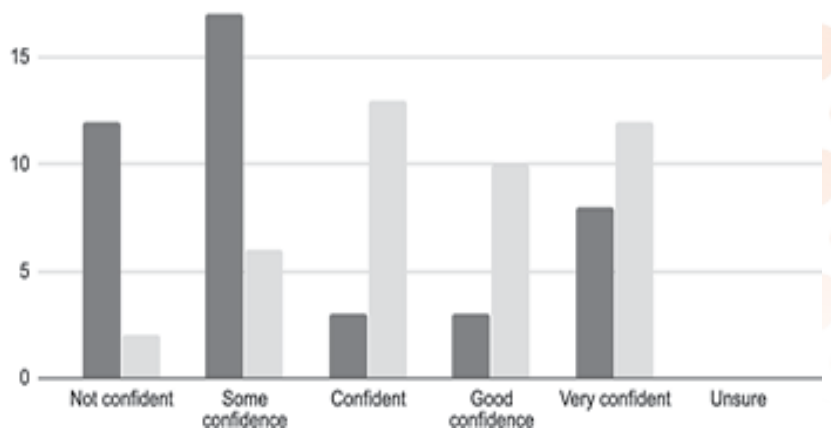

Figure 6: Speaking: Bar graph displaying the degree of confidence in relation to speaking the target language.

Finally, in the part relating to new language usage, participants from both groups were asked if they experienced silent moments when using the language learned, to which $70 \%$ of the ADHD group responded with "all the time" or "frequently", compared to only $47 \%$ of the control group. This indicates quite a high percentage of the ADHD group having certain difficulties when speaking the target language.

When asked if learning a new language had helped at work or in a professional capacity, the answers from both groups were quite similar, in the respect that both groups responded quite favorably to this question. However, when asked to describe their present level of language knowledge, the most negative answers were from the ADHD group, with 56\% responding either the need for some improvement, for a lot of improvement or the need to start again, compared to only $7 \%$ of the control group responding with the need for some improvement.

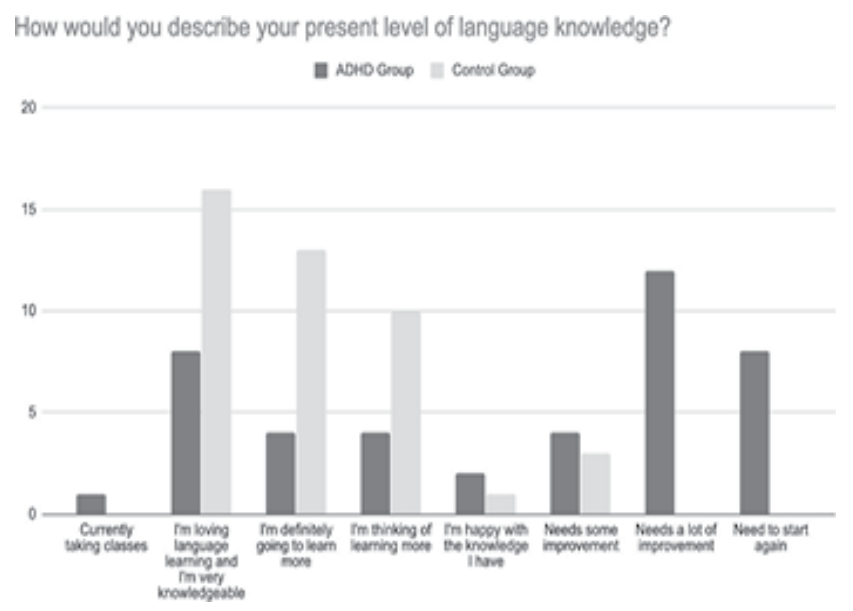

Figure 7: How would you describe your present level of language knowledge: Bar Graph displaying the results relating to the question as to where the learner perceived his or her language level after the language learning process

\section{Discussion}

The question of whether ADHD could affect the language learning process was already addressed with inconclusive findings as to specific difficulties for ADHD diagnosed 
patients [23]. It has been found that students with ADHD can achieve high scores in foreign language classes and Sparks et al. emphasize the diverse cognitive and linguistic profile of individuals with ADHD $[16,22]$. In this empirical study, the findings would suggest that the Attention deficit in ADHD diagnosed patients is in fact a significant factor that could affect the language learning process significantly, as language learning inherently requires the cognitive efficiency of working memory and sufficient attention [21].

Memory; understanding grammar; attention and focus in the sessions; speaking the language; listening to the language; writing the language; reading texts in the language did not seem to present such a high level of difficulty as attention which obtained an extremely significant statistical difference. There was a stark contrast in the opinions of the ADHD group as to their current language level with strong opinions as to the need to improve in comparison to the control group; this echoed the negative answer as to whether the ADHD group felt they had achieved their language goals. As these answers were subjectively responded in this empirical study, they contrasted heavily with the previous results that ADHD could achieve high scores in foreign language classes [16, 22]. It is also interesting to see that the ADHD group were also struggling with the speaking of a foreign language, but this could be a general difficulty for all language learners and also the problem that teachers do not spend enough time for speaking due to a shortage of time or covering textbook topics, thereby emphasizing more reading and writing rather than speaking [26].

The fact that such a high percentage of the ADHD group thought that one to one sessions would be more helpful for them corroborates the importance of individual differences in language learning and would suggest that a one to one environment would help promote more focus and attention for a learner and mitigate potential distractions [27]. Interestingly the ADHD group also thought that visuals would help to improve the learning and this would support the findings that visual explanations have clear benefits to students, both specific and potentially general, with additional benefits to teachers, as visuals can reveal misunderstandings and gaps in knowledge [28-31].

As there are few empirical studies on ADHD in relation to foreign language learning, future research could take on different focus. There could be the additional testing of language abilities connected to an empirical study to assess both quantitative and qualitative. In addition, this particular study had a higher proportion of female participants in both the ADHD group and the control group and this could have an influence on the results. Future studies could also just focus on one language instead of various, as the degree of difficulty of relating to language family knowledge may also affect the learning and these results.

\section{Conclusions}

In conclusion, various inferences can be drawn from this study, which questions whether being diagnosed as having ADHD can affect the language learning process. The conclusion from this study is the impact that attention deficit has on the language learning process as attention was the most difficult to obtain and maintain in the language learning process. From this conclusion, it is hoped that language educators may take into account the findings of this study, really comprehend the attention issues of ADHD learners, and create languagelearning strategies for ADHD language learners. One strategy could be that ADHD learners are recommended to partake individual and personalized courses, as these will be much more tailored to the individual learner and the teacher/trainer will be able to assess ongoing attention and incorporate strategies to enhance, maintain or regain attention according to the needs of the learner. The additional use of multimedia and visuals to enhance attention and learning capacity would also be highly recommended.

\section{References}

1. Kessler RC, Adler L, Barkley R, Joseph Biederman, C Keith Conners, et al. (2006) The prevalence and correlates of adult ADHD in the United States: Results from the national comorbidity survey replication. American Journal of Psychiatry 163: 716-723.

2. Danielson ML, Rebecca H Bitsko, Reem M Ghandour, Joseph R Holbrook, Michael D Kogan, et al. (2016) Prevalence of Parent-Reported ADHD Diagnosis and Associated Treatment Among U.S. Children and Adolescents. Journal of Clinical Child \& Adolescent Psychology 47: 199-212.

3. Simon V, Czobor P, Bálint S, Agnes Mészáros, István Bitter (2009) Prevalence and correlates of adult attentiondeficit hyperactivity disorder: a meta-analysis. British Journal of Psychiatry 194: 204-211.

4. Tannock R (2013) Rethinking ADHD and LD in DSM5: Proposed changes in diagnostic criteria. Journal of Learning Disabilities 46: 5-25.

5. American Psychiatric Association (2017) What Is ADHD? https://www.psychiatry.org/patients-families/adhd/whatis-adhd

6. Safer DJ, Zito JM (1996) Increased methylphenidate usage for attention deficit disorder in the 1990s. Pediatrics 98: 1084.

7. Visser S, Bitsko R, Danielson M, Perou R, Blumberg S (2010) Increasing prevalence of parent-reported attentiondeficit/hyperactivity disorder among children-United States, 2003 and 2007. Morbidity and Mortality Weekly Report 59: 1439-1443.

8. Johnston C, Mash EJ, Miller N, Ninowski JE (2012) Parenting in adults with attention deficit/hyperactivity disorder (ADHD). Clinical Psychology Review 32: 215228.

9. Thakkar VG (2013) Diagnosing the wrong deficit. The New York Times, pp. SR1 LanQua (n.d.). Language Learning. LanQua. https://www.lanqua.eu/theme/ 
language-learning/

10. Byun Y, Ha M, Kwon H, Hong Y, Leem J, et al. (2013) Mobile phone use, blood lead levels, and attention deficit hyperactivity symptoms in children: A longitudinal study. Plos One 8: e59742.

11. Russell G, Ford T, Rosenberg R, Kelly S (2013) The association of attention deficit hyperactivity disorder with socioeconomic disadvantage: Alternative explanations and evidence. Journal of Child Psychology and Psychiatry 55: 436-445.

12. Meerman S, Batstra L, Grietens H, Frances F (2017) ADHD: a critical update for educational professionals. International Journal of Qualitative Studies on Health and Well-being 12: 1298267.

13. Hodge ME (1998) Teaching Foreign Language to At-Risk Learners: A Challenge for the New Millennium. Inquiry 2: $68-78$.

14. Arries JF (1994) An Experimental Spanish Course for Learning Disabled Students. Hispania 77: 110-117.

15. Arries JF (1999) Learning Disabilities and Foreign Languages: A Curriculum Approach to the Design of Inclusive Courses. The Modern Language Journal, 83(1), 98 - 110. JSTOR, www.jstor.org/stable/330409. Accessed 5 Feb. 2020.

16. Sparks RL, Philips L, Javorsky J (2003) Students Classified as LD Who Petitioned for or Fulfilled the College Foreign Language Requirement-Are They Different?: A Replication Study. Journal of Learning Disabilities 36: 348-362.

17. Kramiña I (2000) Lingo Didactic Theories Underlying Multi-Purpose Language Acquisition. Latvia: University of Latvia.

18. Krashen SD (1981) Second language acquisition and second language learning. London: Pergamon Press.

19. Hussain I (2017) Distinction Between Language Acquisition and Language Learning: Comparative Study. Journal of Literature, Languages and Linguistics 39: 1-5.

20. Bachman LF, Palmer AS (1996) Language testing in practice: Designing and developing useful language tests. Oxford: Oxford University Press.

21. Leow RP, Bowles MA (2005) Attention and awareness in SLA. In C. Sanz (Ed.), Mind and context in adult second language acquisition. Methods, theory, and practice. Washington, DC: Georgetown University Press 2005: 179-203.

22. Sparks RL, Javorsky J, Philips L (2005) Comparison of the Performance of College Students Classified as ADHD, $\mathrm{LD}$, and $\mathrm{LD} / \mathrm{ADHD}$ in Foreign Language Courses, Language Learning 55: 151-177.

23. Kałdonek - Crnjakovic A (2018) The cognitive effects of ADHD on learning an additional language. Govor 35: 215-227.

24. Ellis R (2004) The definition and measurement of L2 explicit knowledge. Language Learning 54: 227-275.

25. Pergamon Reber AS, Allen R (2000) Individual differences in implicit learning: Implications for the evolution of consciousness. In R. G. Kunzendorf \& B. Wallace (Eds.), Individual differences in conscious experience: Advances in consciousness research 20: 227-247.

26. Al Hosni S (2014) Speaking Difficulties Encountered by Young EFL Learners. International Journal on Studies in English Language and Literature (IJSELL) 2: 22-30.

27. Ehrman ME, Oxford RL (1995) Cognition plus: Correlates of language learning success. The Modern Language Journal 79: 67-89.

28. Bobek E, Tversky B (2016) Creating visual explanations improves learning. Cognitive research: principles and implications 1: 27.

29. American Psychiatric Association (1968) Diagnostic and statistical manual of mental disorders. 2nd edition (DSMII) Author; Washington, D.C.

30. American Psychiatric Association (1980) Diagnostic and statistical manual of mental disorders. 3rd edition (DSMIII) Author; Washington, D.C.

31. Hamid M, Mohammad D (2016) ADHD and adolescent EFL learners' speaking complexity, accuracy, and fluency in English. Iranian Journal of Language Teaching Research 4: $105-126$.

Copyright: (C2020 Rachel Marie Paling. This is an open-access article distributed under the terms of the Creative Commons Attribution License, which permits unrestricted use, distribution, and reproduction in any medium, provided the original author and source are credited. 